\title{
Body image perception and body composition in early adolescents: a longitudinal study of an Italian cohort
}

Stefania Toselli ${ }^{1}$, Alessia Grigoletto ${ }^{1}$, Luciana Zaccagni ${ }^{2}$, Natascia Rinaldo², Georgian Badicu ${ }^{3^{*}}$ (D, Wilhelm Robert Grosz $z^{3}$ and Francesco Campa ${ }^{4}$

\begin{abstract}
Background: Adolescence is a sensitive period of life in which everyone faces physical and psychological changes. No longitudinal studies considering changes in body image perception and body composition in Italian adolescents have been carried out. The aims of this study were to evaluate the longitudinal change in body composition and weight status in a sample of Italian students of both sexes over the 3 years of middle school and to analyse the influence of these parameters on the perception and satisfaction of one's own body image.
\end{abstract}

Methods: Sixty-four males and seventy females were followed longitudinally from 11 to 14 . Age at first measurement was $11.8 \pm 0.3 \mathrm{yrs}$. in males and $11.9 \pm 0.3 \mathrm{yrs}$. in females, then the students were measured again after 1 year and 2 years. Anthropometric measurements were collected and body composition was assessed by skinfolds. Maturity status was detected by age at menarche in females and by estimated age at peak height velocity in males; sports practice was assessed by a questionnaire. Body Silhouette Charts were used to assess body image perception. The degree of body image dissatisfaction and improper perception of weight status were evaluated. Univariate and multivariate analyses were applied.

Results: Height, sitting height, leg length, and weight increments were higher in males than in females, and in both sexes the sitting height increment was higher than that of leg length. Skinfold thicknesses and percentage of body fat, showed a decrease in males and an increase in females over the 3 years. About $90 \%$ of the sample practiced sport during the 3 years. No significant variations in body image perception were observed among repeated measures but significantly differences were observed between sexes. Although the girls showed a lower incidence of overweight and obesity than boys, girls had a higher dissatisfaction than males. Males were less accurate in one's perception of one's own weight status.

Conclusions: The changes in body composition observed in the sample of the present study were in accordance with their maturity stage. An increase in parameters connected with adiposity is observed in females and a decrease in males. Body image perception did not seem to change with growth, but associations were found between body image perception and BMI and sex. Monitoring body image perception in young adolescents, especially in females and in overweight/obese subjects, is a priority to prevent nutritional disorders.

Keywords: Body size, Body shape, Health, Fat mass, Adolescence

\footnotetext{
* Correspondence: georgian.badicu@unitbv.ro

${ }^{3}$ Department of Physical Education and Special Motricity, University Transilvania of Brasov, 500068 Brasov, Romania

Full list of author information is available at the end of the article
}

(c) The Author(s). 2021 Open Access This article is licensed under a Creative Commons Attribution 4.0 International License, which permits use, sharing, adaptation, distribution and reproduction in any medium or format, as long as you give appropriate credit to the original author(s) and the source, provide a link to the Creative Commons licence, and indicate if changes were made. The images or other third party material in this article are included in the article's Creative Commons licence, unless indicated otherwise in a credit line to the material. If material is not included in the article's Creative Commons licence and your intended use is not permitted by statutory regulation or exceeds the permitted use, you will need to obtain permission directly from the copyright holder. To view a copy of this licence, visit http://creativecommons.org/licenses/by/4.0/ The Creative Commons Public Domain Dedication waiver (http://creativecommons.org/publicdomain/zero/1.0/) applies to the data made available in this article, unless otherwise stated in a credit line to the data. 


\section{Background}

Early adolescence is generally considered the period between 10 and 14 years [1] and starting from this period, during the middle school, most students face physical and psychological changes. This early stage of adolescence is characterised by growth spurt and is soon followed by the development of secondary sexual characteristics. Given the changes that characterize adolescent development, it is not surprising that there are also significant changes in the types and frequency of health problems and psychological disorders during this period, as compared to childhood [2]. Many of the healthrelated behaviours that arise during adolescence have implications for both present and future health and development. For example, obesity in early adolescence not only compromises adolescent development but it also predicts health-compromising obesity in later life, with serious implications for public health [3].

Adolescence is in fact considered a critical window for the development of overweight and obesity and there is consistent evidence showing that excess weight in youth tends to track into adulthood [4,5]. The evaluation of these disorders in adolescents is thus a priority. Overweight and obesity are public health problems and the prevalence among 11-year-olds was greater than $10 \%$ for boys in four countries in Europe (Croatia, Greece, Portugal and the Former Yugoslav Republic of Macedonia), but only two countries (Greece and Italy) had a prevalence of more than $5 \%$ of overweight and obese girls. Obesity during adolescence is associated with morbidities during this phase and also throughout adult life, with eating disorders (ED) being the third most common chronic disease in adolescence, behind only obesity and asthma [6,7]. Nevertheless, longitudinal data regarding overweight/obesity prevalence during early adolescence in Italy are lacking.

The fast morphological and psychosocial changes occurring during this period greatly influence body perception $[8,9]$. Adolescence represents a critical stage in the development of positive or negative body image $[10,11]$. Rapid changes during adolescence in shape and weight due to puberty interact with socio-cultural contexts in influencing body image perceptions [10]. Weight misperception, a perceptual aspect of body image relating to over- or under-estimation of weight, is a separate construct from body dissatisfaction [12-17], since one can be quite accurate in the perception of one's own size and shape, and yet still be dissatisfied. The nurturing of a healthy body image perception is a challenge during adolescence. Early adolescence represents a key developmental transition. The examination of body image during this transitional period is imperative, since distinct and significant changes occur at these times. During early adolescence, for example, most girls place high importance on peer acceptance [18]. Among adolescents, there is often a desire and constant search for physical characteristics other than reality [19], which can cause body image dissatisfaction $[9,20,21]$. In today's societies, there is an idealisation of a perfect body, which, in adolescents, if not achieved, could lead to body image disorders, in addition to the effects on health and behaviour [22-24].

There are several biological factors that influence the risk for body image disturbance during adolescence: age, sex, puberty, and body composition [25], and everyone deserves attention. Body mass index is the most commonly used anthropometric indicator in the body image literature. However, BMI has been criticized because it does not discriminate among the various components of body composition, namely fat mass (FM) and fat-free mass (FFM, including muscle mass, bone, and vital organs); BMI can be considered a raw body composition's indicator [26]. Nevertheless, the assessment of body composition has been rarely considered in body image literature and this has led to an incomplete understanding of how the influence of BMI on body image may differ from that of FM, FFM and of parameters connected with body fat (skinfolds, waist and hip circumferences and waist-hip and waist-height ratios) [26-28]. This aspect is not to be underestimated, especially considering the sex differences in body composition and in body image perception and dissatisfaction. As regards puberty, research has particularly focused on the association between the onset and progression of sexual maturation and psychological and behavioural health consequences [29]. The continuous changes in body growth and psychological development can determine different levels of dissatisfaction of the body image between the different stages of pubertal development [30]. Puberty or changes in maturity status are the most salient developmental milestones during early adolescence and have important implications for self-esteem, body image and psychosocial adjustments [31]. For example, physical selfperception may become less positive with advancing maturity status possibly because of increased adiposity and body dissatisfaction [32, 33]. Also for this aspect, the studies related to the perception of the body image are limited [30, 31, 34].

Nutritional issues in adolescence are mainly characterized by increased energy and nutrient requirements and changes in dietary habits, which could induce overweight and obesity [35]. Adolescents frequently follow eating and behavioural patterns characterised by high-energy (mainly fat) food, skipping daily meals, low fruit and vegetables consumption and an increasingly sedentary routine with many hours in front of the computer and television screen and fewer hours of physical exercise [35]. These kinds of behaviour could determine a greater effort to maintain a 
lean body and achieve the ideal standard of beauty imposed by the media and society [36].

Change in body composition and weight status during this period can play a determinant role in future outcomes and have socio psychological consequences. The main challenge in clarifying these issues is the lack of longitudinal repeated measures needed to assess developmental changes. Thus, the aim of this study was to examine the trends in body composition and in the prevalence of overweight and obesity, assessed using the Cole cut-off values by sex and age [37, 38], in Italian adolescents followed longitudinally over the 3 years of middle school, also taking into account their maturity status. In addition, we sought to determine whether body composition and weight status during adolescence were associated with the risk of developing body image disturbance. In our opinion, a comprehensive body composition measure, rather than BMI alone, may be needed to disentangle the influences of various body components on body image perception and satisfaction. We expect that adolescence leads to an increase in body image misperception and to a greater dissatisfaction, especially in females, in overweight/obese subjects and in those with higher levels of body fat.

\section{Methods}

\section{Participants and design}

A longitudinal study design was chosen, and data were collected and analysed in a sample of 134 children (64 males and 70 females) attending middle school in the
Emilia Romagna region (northern Italy). The students were measured three times at regular intervals: at first measurement mean age was $11.8 \pm 0.3$ yrs. in males and $11.9 \pm 0.3 \mathrm{yrs}$. in females, then they were measured after 1 year and after 2 years. Only children who received parental written consent and agreed to participate were allowed to take part in the study, without any compensation. The study was approved by the Bioethics Committee of the University of Bologna (approval n. 2.18). A flow chart regarding the selection of the sample is shown in Fig. 1. Only native Italian adolescents with no missing data in all the three measurements were included in the study. Immigrant subjects were excluded since they were not a uniform group, but belonged to different ethnic groups. A trained operator directly collected the anthropometric measurements according to standardized rules described in the Procedures section.

General information about demographic (e.g. sex and age) and sport participation (sport practice - considered as club sports, namely planned sports activities led by staff) and the amount of time involved (hours per week) were collected by a questionnaire. The sport practice frequency of each subject was determined by the hours of sport training during a typical week as declared by the subject.

\section{Procedures}

\section{Anthropometry}

Anthropometric characteristics (height, weight, lengths, waist and hip circumferences and skinfold thicknesses)

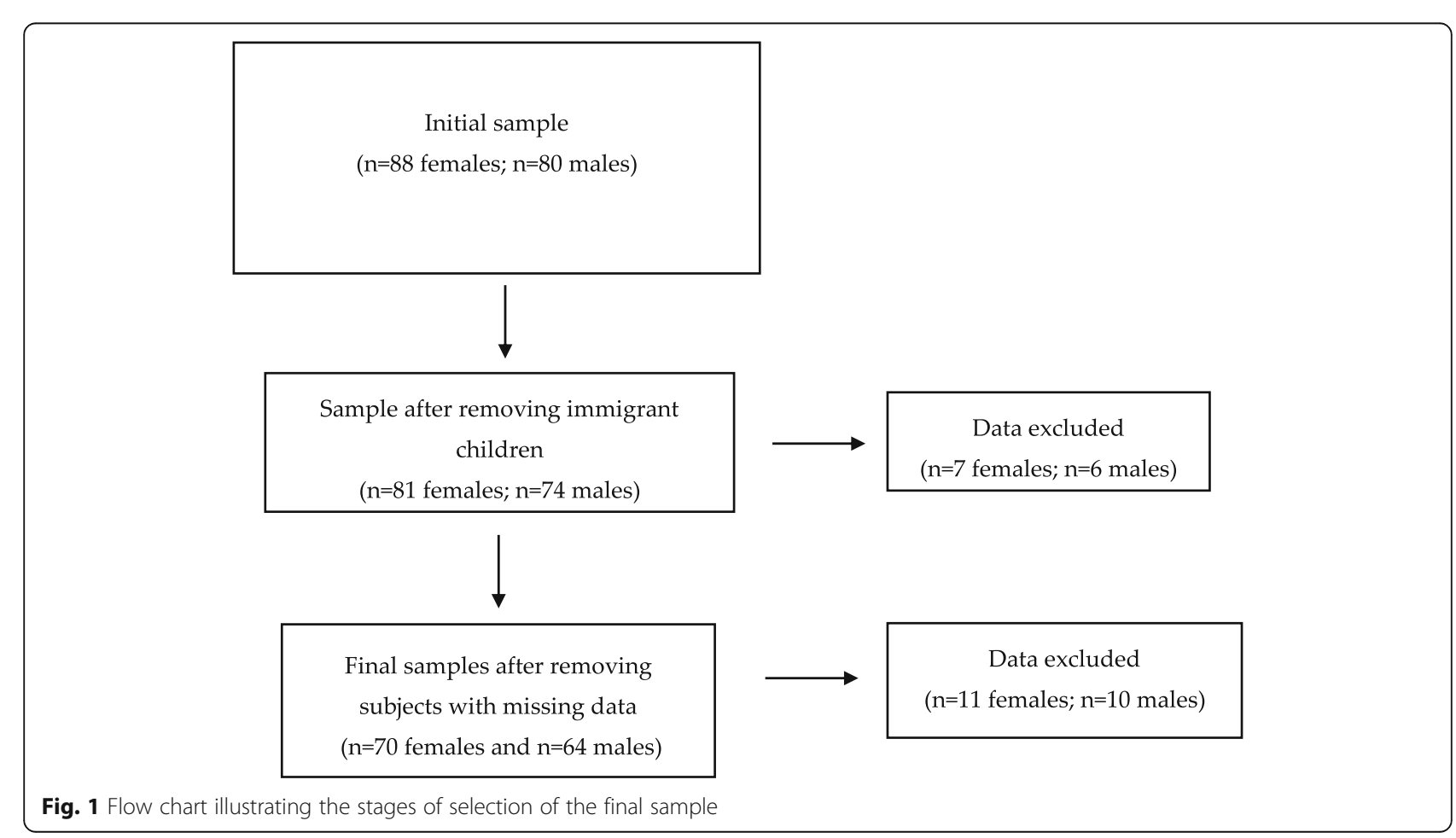


were collected in the morning according to standardised procedures $[39,40]$. Height and sitting height were measured to the nearest $0.1 \mathrm{~cm}$ using a stadiometer (GPM, Zurich, Switzerland), and leg length was derived by the subtraction of sitting height from height. Body weight was measured to the nearest $0.1 \mathrm{~kg}$ (light indoor clothing, without shoes) using a calibrated electronic scale. Circumferences were measured to the nearest $0.1 \mathrm{~cm}$ with a non-stretchable tape. Skinfold thicknesses were measured to the nearest $0.1 \mathrm{~mm}$ using a Lange skinfold caliper (Beta Technology Inc., Houston, TX, USA).

Body mass index (BMI) was calculated as weight (in kilograms) divided by the square of height (in metres). This index was used to assess the weight status of each participant: each subject was thus classified into underweight, normal weight, overweight or obese according to the Cole cut-off values by sex and age [37, 38].

The cormic index was calculated as sitting height (in centimetres)* 100 divided by height (in centimetres).

Waist/Hip ratio (WHR) and Waist/height ratio (WHtR) were calculated, and for the last index children were stratified into two categories $(\leq 0.5$ and $>$ 0.5 ); the value of 0.5 was chosen as cut-off for cardiovascular risk [41-43].

Body composition parameters (percentage of fat mass $(\% \mathrm{~F})$, Fat mass (FM) and Fat free mass (FFM) were calculated using the skinfold equations developed by Slaughter and colleagues [44].

\section{Maturity status}

In girls, maturity status was detected by asking the girls if they have already reached menarche, and if the answer was affirmative, the date was recorded. In boys, an estimation of the years from peak height velocity (PHV), which is an indicator for the adolescent growth spurt, was made using the equation for boys developed by Mirwald and colleagues [45], which is able to predict maturity offset in youngs $[46,47]$. In accordance with Mirwald et al. [45] boys were classified as early, average and late maturers.

Maturity offset $=-9.236+0.0002708$ (leg length * sitting height) -0.001663 (age * leg length) +0.007216 (age * sitting height) +0.02292 (weight/height).

Since maturity offset represents the time before or after PHV, the years from PHV were calculated by subtracting age at PHV from chronological age.

\section{Body image perception}

Body image perception was assessed using the Body Silhouette Chart [48]. The students were shown nine male or female silhouettes, ordered in morphology from emaciation to obesity. Subjects were asked to select the silhouette which they believed was most similar to their own (perceived current figure) as well as the silhouette which they most desired (ideal figure). Using the classification reported by Sánchez-Villegas et al. [48], the silhouette series were divided into four categories (underweight, normal weight, overweight and obese). The discrepancy between the perceived current figure and the ideal figure represents the degree of body image dissatisfaction (FID or Feel minus Ideal Discrepancy) [49]. The FID index was calculated by subtracting the score of the figure selected by children as the ideal figure from the one selected as their perceived current Fig. A positive FID score indicates that the perceived current figure was bigger than the ideal figure and a negative score indicates that the perceived current figure was thinner than the ideal Fig. A FID score of 0 indicates no discrepancy (same figure chosen as perceived current figure and as ideal).

Improper perception of weight status was evaluated by means of FAI (Feel weight status minus Actual weight status Inconsistency) [50]: we calculated the FAI inconsistency by subtracting the conventional code assigned to the real weight status of the participant, according to the BMI assessed by Cole cut-off values by sex and age [37, 38], $(1=$ underweight; $2=$ normal weight; $3=$ overweight; 4 =obese), from the code of her/his perceived weight status $(1=$ underweight; $2=$ normal weight; $3=$ overweight; 4 =obese), obtained using the classification recommended by Sánchez-Villegas et al. [48], which assigns a specific weight status category to each silhouette. According to this classification, silhouettes 1,2 and 3 correspond to underweight $(=1)$, silhouettes 4 and 5 correspond to normal weight $(=2)$, silhouettes 6 and 7 correspond to overweight $(=3)$, silhouettes 8 and 9 correspond to obesity $(=4)$. A FAI score of zero indicates no inconsistency in weight status perception; a positive score indicates that weight status is overestimated, and a negative score indicates that weight status is underestimated.

\section{Statistical analysis}

The data analysis was performed using Statistica for Windows, version 8.0 (Stat Soft Italia SRL, Vigonza, Padua, Italy).

The suitability of the sample size for each analysis was assessed using the G-Power software 3.1.9.2. An a priori power analysis was conducted to ensure that the number of participants was representative for the purposes of this study. To identify the sample size for the study, we assessed an 'a priori: computer required sample sizegiven $\alpha$, power and Effect Size' by G*Power (3.1.9.2, Universität Kiel, Germany). A repeated measures ANOVA was selected as the $\mathrm{F}$ test of all the test family, imputing the following parameters: $\alpha=0.05 ;(1-\beta)=0.95$; Effect Size $f=0.25$; number of groups: 2 ; number of measurements: 3. The outcomes parameters thus calculated 
detected a sample size of 44 participants, but additional subjects were involved to ensure availability of data in case of problems with data collection.

Variables normality was verified with the ShapiroWilk test. The means and SD of the baseline data ( $1^{\text {st }}$ class) and in the following years (2nd and 3rd classes) were calculated. Percentage frequency was determined for qualitative variables (weight status).

Repeated measures ANOVA was used to assess differences between the values carried out on subjects in each of the 3 years of measurement (from first class to third class), while non parametric ANOVA was used to evaluate the differences among body image parameters, since they are not normally distributed.

Differences in the frequencies were tested by the chisquared test. Since in the present study the comparison between the weight status consisted of multiple pairwise comparisons (three groups), according to Bonferroni correction, the results were considered statistically significant if $\mathrm{p}$ was $<0.05 / 3$ or 0.017 .

Backward multiple regression analysis was carried out to assess possible predictors of FID and FAI. Anthropometric variables, sex, weight status and maturity status were included into the model. Predictors input into the model were those found to have significant associations with FID and FAI (i.e., $p<0.05$ ), while those with $p>$ 0.05 were removed from the model.

\section{Results}

\section{Anthropometry}

Table 1 shows the anthropometric and body composition characteristics of the sample during the three consecutive years in both sexes. Considering sex differences, ANOVA showed significant differences in body proportion (leg length and cormic index), in waist and hip circumferences and relative indexes (WHR and WHtR), in three skinfold thicknesses (suprailiac, medial calf and thigh) and in the sum of skinfolds.

Greater are the differences connected with the variation of the measurement over time. Except for cormic index, WHtR, three of skinfold thickness and \%F, all the other characters presented a significant variation with age.

Analysing these variations in more detail, considering also the post-hoc, we can observe some different trend in the two sexes. In males, from the 1st to the 3rd class, height increment was $13.43 \pm 4.24 \mathrm{~cm}$, sitting height increment $6.21 \pm 3.48 \mathrm{~cm}$, leg length increment $7.23 \pm 2.45$ $\mathrm{cm}$ and weight increment $11.03 \pm 4.15 \mathrm{~kg}$.

The cormic index, which indicates the percentage of the sitting height on the total height, showed a slight tendency to decrease, with significant difference between the 1 st and the 3rd class $(p=0.047)$. BMI presented a slight increase. On average, WHtR remained stable over the 3 years: a small percentage of boys presented WHtR values higher than the 0.5 cut-off (7.69\% in the 1st class; 9.52\% in the 2nd and 3rd classes). WHR showed a significant decrease with age.

In general, skinfold thicknesses remained quite stable over the 3 years, with a general tendency to decrease. However, the decrease observed for biceps, triceps and thigh skinfolds was significant $(p<0.05)$.

Fat Percentage significantly decreased with age, particularly between the 1 st and the 3rd class $(p<0.001)$, while FFM significantly increased $(\mathrm{p}<0.001)$.

Ninety-two percent of males practiced club sports. This percentage was constant in the first 2 years, with a slight decrease $(90 \%)$ in the 3rd class. Weekly amount of club sports increased with age, with significant difference between the 1st and 3rd class.

In females, from the 1st to the 3rd class, height increment was $7.32 \pm 3.51 \mathrm{~cm}$, sitting height increment $4.40 \pm$ $2.55 \mathrm{~cm}$, leg length increment $2.92 \pm 2.45 \mathrm{~cm}$ and weight increment $8.88 \pm 4.15 \mathrm{~kg}$. The cormic index did not show any significant variation with age, even though a tendency to increase was observed. BMI showed a significant increase between all the age classes $(p<0.001)$. Waist and hip circumferences showed a significant increase with age $(p<0.05)$, so that WHR showed a slight decrease with age, but not significant. WHtR did not show any significant differences during the 3 years, and also the subjects with values above the cut off remained stable over the 3 years $(9.52 \%)$.

Almost all skinfold thicknesses showed a significant increase $(p<0.001)$, except for the biceps, subscapular and medial calf. This influenced body composition parameters, which significantly increased with age $(\mathrm{p}<$ 0.001 ). In particular, $\% \mathrm{~F}$ increased from $19.55 \%$ in the 1 st class to $22.19 \%$ in the 3 rd class.

Sports were practiced by $89.9 \%$ of the girls in the first class, passing to $87.1 \%$ in the second class and to $90 \%$ in the $3^{\text {rd }}$ class. Weekly amount of club sports slightly increased during the 3 years, but not significantly.

\section{Weight status}

Considering the prevalence of weight status in males (Table 2), no significant differences were observed among the 3 years. Normal weight prevailed in all the considered classes, showing an increasing trend with age. A small percentage of obese boys were observed in the 1st class, but this category disappeared in the following years, and a reduction of overweight subjects was observed.

Similarly, in females the weight status prevalence did not significantly differ among the 3 years and normal weight subjects prevailed (Table 2). Contrarily to males, in the 1st and 2nd classes a small percentage of underweight girls were observed. Even if the differences were 


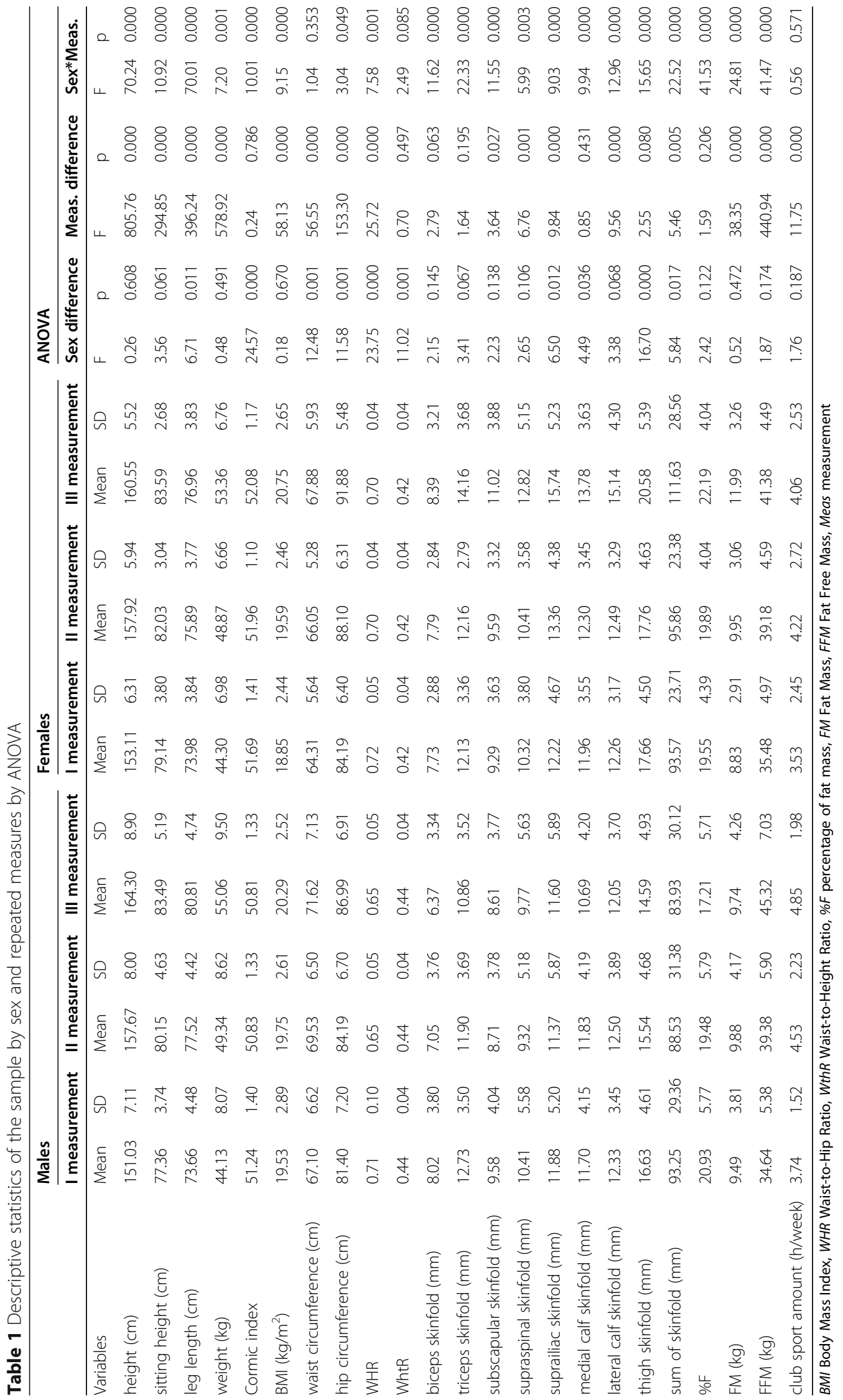


Table 2 Prevalence of weight status (according Cole cut-off) in the different measurements

\begin{tabular}{llll}
\hline & $\begin{array}{l}\text { I measurement } \\
(\%)\end{array}$ & $\begin{array}{l}\text { II measurement } \\
(\%)\end{array}$ & $\begin{array}{l}\text { III measurement } \\
(\%)\end{array}$ \\
\hline $\begin{array}{llll}\text { Males } \\
\text { normal weight }\end{array}$ & 68.75 & 76.19 & 77.78 \\
overweight & 26.56 & 23.81 & 22.22 \\
obese & 4.69 & 0.00 & 0.00 \\
$\begin{array}{l}\text { Females } \\
\text { underweight }\end{array}$ & 1.47 & & \\
normal weight & 82.35 & 1.47 & 0.00 \\
overweight & 14.71 & 85.71 & 82.86 \\
obese & 1.47 & 12.83 & 17.14 \\
\hline
\end{tabular}

not significant, a slight increase in the prevalence of overweight in the 3rd class was observed.

\section{Maturity status}

According to equation of Mirwald et al. [45] the mean age at PHV of the male sample was 14.00 years $(\mathrm{SD}=$ $0.62)$. The majority of the boys were average maturers (91.9\%), only $3.2 \%$ were early maturers, and $4.8 \%$ late maturers. In the 3rd class about $93 \%$ of the subjects were approaching the PHV (distance from $\mathrm{PHV}= \pm 0.5$ years).

With reference to females, data regarding age at menarche showed that in the 1st class, $29.0 \%$ of the sample had reached it; this percentage increased to $62.9 \%$ in the $2^{\text {nd }}$ class and to $74.3 \%$ in the 3rd class. The mean age at menarche was 11.97 ( $\mathrm{SD}=0.94$ years $)$.

\section{Body image perception}

Body image perception showed significant differences between sexes (Table 3). The difference in the choice of perceived current figures was significant, since females have chosen thinner silhouettes than males. Body image dissatisfaction (FID) is greater in females. Males presented a greater misperception of their weight status, showing a greater underestimation than females.

Body image parameters did not show any significant variations with age (Table 3 ). In all 3 years, on average, males chose normal weight silhouettes both for the perceived current figure and the ideal figure. As a consequence, the FID score indicated no dissatisfaction with their body, especially in the 3rd class. As regards the misperception of their weight status, FAI score indicated no variations with age; a tendency to underestimate the weight status was observed in all the three considered years.

On average, the perceived current figure chosen by girls (Table 3 ) belonged to the normal weight category, but it was in the upper extremity (nearly overweight). The mean ideal figure chosen also falls into the normal weight category, but presented lower values than the perceived current figure, as testified by positive mean values of FID, indicating a desire to be thinner. FAI score approximated zero, indicating no inconsistency in the perception of weight status, even though with a slight tendency to underestimation, testified by negative mean values.

\section{Predictors of FID and FAI}

We performed different multiple linear regression models to evaluate the impact of age, sex and BMI on body image dissatisfaction (assessed by FID score) and on inconsistency of weight status (assessed by FAI score) in the adolescents during their 3 years of middle school (1st class, 2nd class, and 3rd class). The results of these predictive models are presented in Table 4.

As regards FID, both sex and BMI are significantly associated with FID and both are positive predictors. Body image dissatisfaction increases as BMI increases and being a female increases the dissatisfaction. The models explain $16 \%$ of the variance in the 1 st class, $39 \%$ in the 2nd class and $52 \%$ in the 3rd class; all models have highly significant $\mathrm{R}^{2}$.

Being females is associated with a higher overestimation of one's own weight status, as shown by the significant and positive association between sex and FAI (Table 4). In the transition to the 2nd class and 3rd class, the adolescents showed an increase of overestimation as their BMI increased. The models explain 5\% of the variance in the 1 st class, $17 \%$ in the 2 nd class and $20 \%$ in the 3rd class; all models have highly significant $\mathrm{R}^{2}$.

\section{Discussion}

Trends in body composition and weight status

The present study considered the trends in body composition and in the prevalence of overweight and obesity, assessed using the Cole cut-off values [37, 38], in Italian adolescents followed longitudinally over the 3 years of 


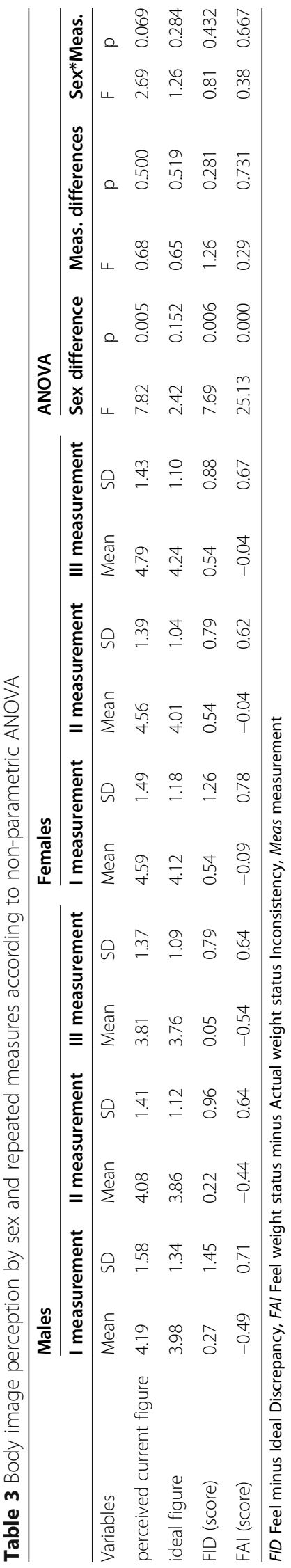


Table 4 Predictors of FID (Feel minus Ideal Discrepancy) and FAl (Feel weight status minus Actual weight status Inconsistency): results of multiple regression analysis

\begin{tabular}{|c|c|c|c|c|c|c|c|c|c|}
\hline \multirow{2}{*}{$\begin{array}{l}\text { Variables } \\
\text { FID }\end{array}$} & \multicolumn{3}{|c|}{ I measurement } & \multicolumn{3}{|c|}{ II measurement } & \multicolumn{3}{|c|}{ III measurement } \\
\hline & $\beta$ & $t$ & $\mathrm{p}$ & $\beta$ & $\mathbf{t}$ & $p$ & $\beta$ & $\mathbf{t}$ & $p$ \\
\hline Age & -0.118 & -1.488 & 0.139 & -0.124 & -1.827 & 0.070 & -0.022 & -0.373 & 0.710 \\
\hline BMI & 0.402 & 5.056 & 0.000 & 0.596 & 8.821 & 0.000 & 0.675 & 11.176 & 0.000 \\
\hline Sex (female) & 0.164 & 2.057 & 0.042 & 0.203 & 3.001 & 0.003 & 0.226 & 3.735 & 0.000 \\
\hline$R^{2}$ & 0.183 & & & 0.407 & & & 0.533 & & \\
\hline Adjusted $R^{2}$ & 0.164 & & & 0.393 & & & 0.523 & & \\
\hline$p$ & 0.000 & & & 0.000 & & & 0.000 & & \\
\hline FAI & $\beta$ & $\mathrm{t}$ & $p$ & $\beta$ & $\mathbf{t}$ & $p$ & $\beta$ & $\mathbf{t}$ & $p$ \\
\hline Age & 0.024 & 0.285 & 0.776 & -0.027 & -0.343 & 0.732 & 0.109 & 1.403 & 0.163 \\
\hline BMI & 0.054 & 0.642 & 0.522 & 0.307 & 3.885 & 0.000 & 0.289 & 3.711 & 0.000 \\
\hline Sex (female) & 0.269 & 3.164 & 0.002 & 0.316 & 3.982 & 0.000 & 0.322 & 4.111 & 0.000 \\
\hline$R^{2}$ & 0.074 & & & 0.189 & & & & 0.222 & \\
\hline Adjusted $R^{2}$ & 0.053 & & & 0.170 & & & & 0.203 & \\
\hline$p$ & 0.018 & & & 0.000 & & & & 0.000 & \\
\hline
\end{tabular}

$\beta$ regression coefficient, $B M I$ Body Mass Index

middle school. In addition, another aim was to determine whether body composition and weight status during adolescence were associated with the risk of developing body image disturbance. To our knowledge, this study is the first to evaluate the longitudinal association between these parameters in young Italian adolescents.

As regards the first aim, the longitudinal variations in body composition of the subjects of the two sexes are connected with the phase of maturation they were approaching.

The male sample during the 3 years was approaching the growth spurt, and in the last year of measurement about $93 \%$ of the boys were near the time of PHV. This is reflected in the great height increment and in the prevalence of leg length growth in comparison with trunk growth. Differential timings of growth of height, sitting height and leg length are in fact known, since with growth a change in relationship between leg length and sitting height is observed. The growth of leg length precedes the PHV, while sitting height growth occurs after PHV [32]. The trend in parameters connected with body composition confirmed this specific stage of growth. During the 3 years, the sum of skinfolds showed a tendency to decrease in males, and, as a consequence, a significant decrease of $\% \mathrm{~F}$ with age was observed, accompanied by a significant increase of FFM were observed. These data are in accordance with the body composition and fat distribution changes that occur during male adolescence [32].

The percentage of mature girls increased with age, changing from $29.0 \%$ in the $1^{\text {st }}$ class to $74.3 \%$ in the 3 rd class. The mean age at menarche was $11.97(\mathrm{SD}=0.94$ years). A significant increase with age was observed for all the considered parameters, with height, weight, waist and hip circumferences showing significant differences among all the considered age classes. The height increment was lower than that observed in males, while the sitting height increment was higher than that of leg length: this reflects the different phase of maturation of the two sexes, with girls ahead compared to males.

Also connected with sexual dimorphism is the trend of parameters connected to body composition: skinfold thicknesses generally showed a significant increase in girls during the 3 years; it follows that the \%F significantly increased from $19.55 \%$ in the 1st class to $22.19 \%$ in the 3rd class.

In males, BMI remained quite stable during the three school years. The percentage of normal weight males was lower than the national data [51], which reported an incidence of $75.9 \%$ in 11-years-old boys and $78.4 \%$ in 13-years-old boys, but it tended to approach these values with age. Percentages of overweight boys in the present sample were higher than the national data, but a tendency to decrease with age was observed. Obesity is slightly higher in the 1st class, but disappeared in the following years. Contrarily to the national data, there were no underweight subjects in the present sample. In girls, BMI showed a significant increase. Even if the weight status prevalence did not significantly differ among the 3 years and normal weight subjects prevailed, a reduction in underweight prevalence and a slight increase in the prevalence of overweight with age were observed. The percentage of normal weight girls was 
comparable to the national data [51], but the percentage of overweight girls was higher, and obese and underweight subjects were lower. Regarding sex differences in weight status, females showed a higher incidence of normal weight, and a lower incidence of overweight and obesity.

The latest data [52] from the WHO Childhood Obesity Surveillance Initiative (COSI) reveal that in countries like Italy, Portugal, Spain and Greece, there has been an important decrease of obesity, which is attributable to a very significant effort that these countries have made in recent years in the management and prevention of childhood obesity [53], although rates are still high. Despite the fact that the incidence of overweight in the present sample was high, the percentage of subjects engaged in sports practice (about $90 \%$ in both sexes) suggests that the issue of prevention was taken into account. Low levels of PA in adolescents is a critical cause for the obesity epidemic in developed countries [53, 54], and obese adolescents are generally less physically active (PA) than normal-weight adolescents [55]. As a consequence, increasing physical activity is probably one of the best strategies to reduce the prevalence of overweight and obesity in youth [56]. In addition, fat distribution may have more significant implications for health than the total amount of body fat. In the present study only a small percentage of subjects of both sexes presented a WHtR higher than cut-off. Visceral fatness or the accumulation of intraabdominal adipose tissue increases cardiovascular risk in children, and it has been shown that that the most active individuals have the lowest visceral fat after adjusting for total body fat. This suggests that PA may elicit a proportionally larger decrease in fat stored in the intra-abdominal cavity than in other regions in people with visceral fatness $[57,58]$. Crosssectional data also suggest that PA could promote a reduction of visceral fat and trunk fat in pre-pubertal and pubertal children [59, 60]. In this longitudinal study, sports practice is high and regular, and once again this can be traced back to the preventive campaigns that the region in which the study took place [61] has put in place to encourage the spread of a healthy lifestyle among children and adolescents.

\section{Association between anthropometric change and body image perception}

The second aim was to assess whether the change in body composition parameters and weight status influence body image perception. In both sexes, body image perception did not show any significant variations with age and both the perceived current figure and the ideal figures were chosen fall into the category of average in normal weight silhouettes. Nevertheless, females tend to choose a thinner ideal figure than the perceived current figure, as also testified by the FID. The average FAI index of both sexes is close to 0 , implying a correct perception of their own weight status.

The data of the present study strengthen the notion that body image dissatisfaction and perception are mostly influenced by moderating factors such as sex and BMI, which should be considered in studies regarding youth. The results of the multiple linear regression analysis showed that BMI is a common denominator for both sexes, and as it increases also body dissatisfaction increases. With the increase of BMI, in the adolescents of the 2nd class and 3rd class, increases the overestimation of their weight status. In addition, girls are more vulnerable than males for both dissatisfaction. In girls, fat mass increases more rapidly than in boys during adolescence. Important variations in body composition, which are influenced by age and sex, and which include BMI, subcutaneous fat and relative fat distribution [31, 62-64] can be sources of dissatisfaction in body image perception.

The results of the present study are in accordance with those of other Authors [65-67], which showed that increased BMI is a key point in influencing body image perception. It is associated with lower self-perceptions of social acceptance and physical appearance, and subjects who demonstrate low perceptions of self-concept are also generally less willing to participate in activities with peers [68-70].

\section{Strength and limits}

The strength of this study is the three-year longitudinal design in which anthropometric parameters of the adolescents were directly measured by an expert anthropometrist, and not self-reported.

A limitation of this study could be connected to the use of standardized body silhouettes instead of computerized assessments, which allow to assess separate characteristics of body image, such as overall size or shape. This technological method presents a good flexibility to visually represent how users perceive themselves, compared to fixed silhouettes. In addition, it allows detailed information to be gathered regarding the assessments of individual body areas [71, 72]. Even if the silhouettes used in the present study are widely utilized in the literature $[73,74]$ they do not allow the assessments of muscularity, an important aspect considered in studies on older subjects $[75,76]$.

\section{Conclusion}

Adolescence is a complex transition stage, during which, in relation to maturation, significant changes in body composition occur. The adolescents of the present study 
are in the phase where these changes take place, and where body fat percentage increases in females and decreases in males. Even if their body image perception did not seem to change with age, associations were found between body image perception and BMI and sex. Dissatisfaction and overestimation of one's own weight status increase as BMI increases, and in females to a greater extent than in males. The results of the present study do not confirm the initial hypothesis that adolescence in itself leads to an increase in body image misperception, but confirms the greater dissatisfaction of females and of overweight/obese subjects. Monitoring body image perception in young adolescents, especially in females and in subjects with a high BMI, should be a priority in order to prevent nutritional disorders.

\section{Abbreviations \\ FAl: Feel weight status minus Actual weight status Inconsistency; WHO: World Health Organization; ED: Eating disorders; BMI: Body mass index; WHR: Waist/Hip ratio; WHtR: Waist/height ratio; \%F: Percentage of fat mass; FM: Fat mass; FFM: Fat free mass; PHV: Peak height velocity; FID: Feel Ideal Discrepancy; HBSC: Health Behaviour in School-aged Children; PA: Physical Activity; COSI: Childhood Obesity Surveillance Initiative}

\section{Acknowledgments}

The authors are grateful to all people who took part in this study.

\section{Authors' contributions}

Conceptualization, S.T, A.G. and L.Z; methodology, S.T., N.R., L.Z. and F.C.; software, S.T. and F.C.; formal analysis, S.T., A.G. and L.Z.; investigation, S.T., A.G., L.Z. and N.R.; data curation, S.T.; writing -original draft preparation, S.T. and F.C; writing-review and editing, S.T, A.G., L.Z., N.R., G.B. and F.C; visualization, S.T, A.G., L.Z., N.R., G.B., W.R.G. and F.C; supervision, S.T, A.G., L.Z., N.R., G.B. and F.C. All authors have read and agreed to the published version of the manuscript.

\section{Funding}

This research received no external funding.

\section{Availability of data and materials}

The datasets used during the current study are available from the corresponding author on reasonable request.

\section{Declarations}

\section{Ethics approval and consent to participate}

The study was approved by the Bioethics Committee of the University of Bologna (approval n. 2.18). Only children who received parental written consent were allowed to take part in the study.

\section{Consent for publication}

Not applicable.

\section{Competing interests}

The authors declare that they have no competing interests.

\section{Author details}

'Department of Biomedical and Neuromotor Sciences, University of Bologna, 40126 Bologna, Italy. ${ }^{2}$ Department of Neuroscience and Rehabilitation, Faculty of Medicine, Pharmacy and Prevention, University of Ferrara, 44121 Ferrara, Italy. ${ }^{3}$ Department of Physical Education and Special Motricity, University Transilvania of Brasov, 500068 Brasov, Romania. ${ }^{4}$ Department for Life Quality Studies, University of Bologna, 47921 Rimini, Italy.
Received: 25 August 2020 Accepted: 6 July 2021

Published online: 12 July 2021

\section{References}

1. World Health Organization. Orientation Programme on Adolescent Health for Health-care Providers. In https://www.who.int/maternal_child_ adolescent/documents/pdfs/9241591269_op_handout.pdf, Accessed 10 June 2020.

2. Holmbeck GN. A developmental perspective on adolescent health and illness: an introduction to the special issues. J Pediatr Psychol. 2002;27(5): 409-16. https://doi.org/10.1093/jpepsy/27.5.409.

3. Simmonds M, Llewellyn A, Owen CG, Woolacott N. Predicting adult obesity from childhood obesity: a systematic review and meta-analysis. Obes Rev. 2016;17(2):95-107. https://doi.org/10.1111/obr.12334.

4. de Souza MC, Eisenmann JC, DV e S, de Chaves RN, de Moraes Forjaz CL, JAR M. Modeling the dynamics of BMI changes during adolescence. The Oporto growth, health and performance study. Int J Obes. 2015;39(7):10639. https://doi.org/10.1038/ijo.2015.60.

5. Barraco GM, Luciano R, Semeraro M, Prieto-Hontoria PL, Manco M. Recently discovered Adipokines and cardio-metabolic comorbidities in childhood obesity. Int J Mol Sci. 2014;15(11):19760-76. https://doi.org/10.3390/ijms1 51119760.

6. Godsey J. The role of mindfulness based interventions in the treatment of obesity and eating disorders: an integrative review. Complement Ther Med. 2013;21(4):430-9. https://doi.org/10.1016/j.ctim.2013.06.003.

7. Golden NH, Schneider M, Wood C, COMMITTEE ON NUTRITION; COMMITTEE ON ADOLESCENCE; SECTION ON OBESITY. Preventing Obesity and Eating Disorders in Adolescents. Pediatrics. 2016;138:e20161649.

8. Castro IRR, Levy RB, Cardoso LO, Passos MD, Sardinha LMV, Tavares LF, et al. Imagem corporal, estado nutricional e comportamento comrelacao ao peso entre adolescentes brasileiros. Cienc Saude Coltiva. 2010;15(suppl 2):30994108. https://doi.org/10.1590/S1413-81232010000800014.

9. de Pinho L, Santos Figueiredo Brito MF, Ramos Veloso Silva R, Brito Messias R, de de Oliveira e Silva CS, Barbosa DA, Prates Caldeira A. Perception of body image and nutritional status in adolescents of public schools. Rev Bras Enferm 2019; 72:229-235, suppl 2, DOl: https://doi.org/10.1590/0034-7167-2 018-0644.

10. Voelker DK, Reel JJ, Greenleaf C. Weight status and body image perceptions in adolescents: current perspectives. Adolesc Health Med. 2015;6:149-58.

11. Elia C, Karamanos A, Silva MJ, O'Connor M, Lu Y, Dregan A, et al. Weight misperception and psychological symptoms from adolescence to young adulthood: longitudinal study of an ethnically diverse UK cohort. BMC Public Health. 2020;20(1):712. https://doi.org/10.1186/s12889-020-08823-1.

12. Challinor KL, Mond J, Stephen ID, Mitchison D, Stevenson RJ, Hay P, et al. Body size and shape misperception and visual adaptation: an overview of an emerging research paradigm. J Int Med Res. 2017;45(6):2001-8. https:// doi.org/10.1177/0300060517726440.

13. Toselli S, Spiga F. Sport practice, physical structure, and body image among university students. J Eat Disord. 2017:5:31.

14. Toselli S, Brasili P, Spiga F. Body image, body dissatisfaction and weight status in children from Emilia-Romagna (Italy): comparison between immigrant and native-born. Ann Hum Biol. 2014;41(1):23-8. https://doi.org/1 0.3109/03014460.2013.822557.

15. Gualdi-Russo E, Manzon VS, Masotti S, Toselli S, Albertini A, Celenza F, et al. Weight status and perception of body image in children: the effect of maternal immigrant status. Nutr J. 2012;18:85.

16. Argnani L, Toselli S, Gualdi-Russo E. Body image and growth in Italy. Coll Antropol. 2008;32(2):413-8.

17. Gualdi-Russo E, Albertini A, Argnani L, Celenza F, Nicolucci M, Toselli S Weight status and body image perception in Italian children. J Hum Nutr Diet. 2008;21(1):39-45. https://doi.org/10.1111/j.1365-277X.2007.00843.X.

18. Craike M, Young JA, Symons CM, Pain MD, Harvey JT, Eime RM, et al. Trends in body image of adolescent females in metropolitan and non-metropolitan regions: a longitudinal study. BMC Public Health. 2016;16(1):1143. https://doi. org/10.1186/s12889-016-3815-1.

19. Marques MI, Pimenta J, Reis S, Ferreira LM, Peralta L, Santos MI, et al. (In) Satisfacao com a imagem corporal na adolescencia. Nascer Crescer. 2018;25: 217-21.

20. Lira AG, Ganen AP, Lodi AS, Alvarenga MS. Uso de redes sociais, influencia da midia e insatisfacao com a imagem corporal de adolescents brasileiras. J Bras Psiquiatr. 2017;6:164-71. 
21. Pelegrini A, Petroski EL. The association between body dissatisfaction and nutritional status in adolescents. Human Movement. 2010;11:51-7.

22. Lewer M, Bauer A, Hartmann AS, Vocks S. Different facets of body image disturbance in binge eating disorder: a review. Nutrients. 2017;9(12):1294. https://doi.org/10.3390/nu9121294.

23. Petroski EL, Pelegrini A, Glaner MF. Motivos e prevalencia de insatisfacao com a imagem corporal em adolescentes. Cienc Saude Coletiva. 2012;17(4): 1071-7. https://doi.org/10.1590/S1413-81232012000400028.

24. Karazsia BT, Murnen S, Tylka TL. Is body dissatisfaction changing across time? A cross-temporal meta-analysis. Psychol Bull. 2017;143(3):293-320. https://doi.org/10.1037/bul0000081.

25. Santana ML, Silva Rde C, Assis AM, Raich RM, Machado ME, de J Pinto E, et al. Factors associated with body image dissatisfaction among adolescents in public schools students in Salvador, Brazil. Nutr Hosp. 2013;28(3):747-55. https://doi.org/10.3305/nh.2013.28.3.6281.

26. Streeter VM, Milhausen RR, Buchholz AC. Body image, body mass index, and body composition in young adults. Can J Diet Pract Res. 2012;73(2):78-83. https://doi.org/10.3148/73.2.2012.78.

27. Veses AM, Martínez-Gómez D, Gómez-Martínez S, Zapatera B, Veiga ÓL, Marcos A. Association between excessive body fat and eating-disorder risk in adolescents: the AFINOS study. Med Clínica. 2011;136(14):620-2. https:// doi.org/10.1016/j.medcli.2010.09.042.

28. Babio N, Canals J, Pietrobelli A, Pérez S, Arija V. A two-phase population study: relationships between overweight, body composition and risk of eating disorders. Nutr Hosp. 2009;24(4):485-91.

29. Lee CT, Tsai MC, Lin CY, Strong C. Longitudinal Effects of Self-Report Pubertal Timing and Menarcheal Age on Adolescent Psychological and Behavioral Outcomes in Female Youths from Northern Taiwan. Pediatr Neonatol. 2017;58(4):313-20. https://doi.org/10.1016/j.pedneo.2016.04.004.

30. Zhang Y, Li T, Yao R, Han H, Wu L, Wu X, et al. Comparison of Body-Image Dissatisfaction Among Chinese Children and Adolescents at Different Pubertal Development Stages. Psychol Res Behav Manag. 2020;13:555-62. https://doi.org/10.2147/PRBM.S242645.

31. Altıntaş A, Aşçı FH, Kin-Işler A. Güven-Karahan B, Kelecek S, Özkan A, Yılmaz A, Kara FM. The role of physical activity, body mass index and maturity status in body-related perceptions and self-esteem of adolescents. Ann Hum Biol 2014; 41(5):395-402, DOl: https://doi.org/10.3109/03014460.2013. 857721.

32. Malina RM, Bouchard C, Bar-Or O. Growth, maturation, and physical activity. Champaign: Human Kinetics; 2004. https://doi.org/10.5040/9781492596837.

33. Stice $E$, Whitenton K. Risk factors for body dissatisfaction in adolescent girls: a longitudinal investigation. Dev Psychol. 200;38:669-378.

34. Monsma EV, Malina RM, Feltz DL. Puberty and physical self-perceptions of competitive female figure skaters: an interdisciplinary approach. Res Q Exerc Sport. 2006;77(2):158-66. https://doi.org/10.1080/02701367.2 006.10599350

35. Cecon RS, Franceschini SDCC, Peluzio MDCG, Hermsdorff HHM, Priore SE. Overweight and body image perception in adolescents with triage of eating disorders. Sci World J. 2017;2017:8257329.

36. Pizetta Zordão O, Barbosa A, Sant'Ana Parisi T, Marciano Graselli CS, Alves Nogueira D, Ribeiro SR. Associacao da imagem corporale transtornos alimentares em adolescentes de Minas Gerais (Brasil). Nutr.Clin.Diet.Hosp. 2015;35:48-56.

37. Cole TJ, Lobstein T. Extended international (IOTF) body mass index cut-offs for thinness, Overweight and Obesity. Pediatr Obes. 2012;7(4):284-94. https://doi.org/10.1111/j.2047-6310.2012.00064.x.

38. Cole TJ, Flegal KM, Nicholls D, Jackson AA. Body mass index cut offs to define thinness in children and adolescents. International Survey. Br Med J. 2007;335:194-7.

39. Weiner JS, Lourie JA. Practical Human Biology. Cambridge: Academic Press: MA, USA; 1981.

40. Lohman TG, Roche AF, Martorell R. Anthropometric standardization reference manual. Champain: Human Kinetics Books; 1988.

41. Ashwell $M, H$ sieh SD. Six reasons why the waist-to-height ratio is a rapid and effective global Indicator for health risks of obesity and how its use could simplify the international public health message on obesity. Int J Food Sci Nutr. 2005;56(5):303-7. https://doi.org/10.1080/096374805001 95066.

42. Maffeis C, Banzato C, Talamini G. Waist-to-height ratio, a useful index to identify high metabolic risk in overweight children. J Pediatr. 2008;152(2): 207-13. https://doi.org/10.1016/j.jpeds.2007.09.021.
43. McCarthy HD, Ashwell M. A study of central fatness using waist-to-height ratios in UK children and adolescents over two decades supports the simple message - 'keep your waist circumference to less than half your height'. Int J Obes. 2006;30(6):988-92. https://doi.org/10.1038/sj.ijo.0803226.

44. Slaughter MH, Lohman TG, Boileau RA, Horswill CA, Stillman RJ, Van Loan $M D$, et al. Skinfold equations for estimation of body fatness in children and youth. Hum Biol. 1988;60(5):709-23.

45. Mirwald RL, Baxter-Jones AD, Bailey DA, Beunen GP. An assessment of maturity from anthropometric measurements. Med Sci Sports Exerc. 2002; 34(4):689-94. https://doi.org/10.1097/00005768-200204000-00020.

46. Sherar LB, Mirwald RL, Baxter-Jones AD, Thomis M. Prediction of adult height using maturity-based cumulative height velocity curves. J Pediatr. 2005;147(4):508-14. https://doi.org/10.1016/j.jpeds.2005.04.041.

47. Toselli S, Merni F, Campa F. Height prediction in elite Italian rugby players: a prospective study. Am J Hum Biol. 2019;31:e23288.

48. Sánchez-Villegas A, Madrigal H, Martínez-González MA, Kearney J, Gibney MJ, de Irala J, et al. Perception of body image as indicator of weight status in the European union. J Hum Nutr Diet. 2001;14(2):93-102. https://doi.org/1 0.1046/j.1365-277X.2001.00281.x.

49. Mciza Z, Goedecke JH, Steyn NP, Charlton K, Puoane T, Meltzer S, et al. Development and validation of instruments measuring body image and body weight dissatisfaction in south African mothers and their daughters. Public Health Nutr. 2005;8(5):509-19. https://doi.org/10.1079/PHN2005814.

50. Zaccagni L, Masotti S, Donati R, Mazzoni G, Gualdi-Russo E. Body image and weight perceptions in relation to actual measurements by means of a new index and level of physical activity in Italian university students. J Transl Med. 2014;12:42

51. Health Behaviour in School-aged Children (HBSC) / World Health Organization Collaborative Cross-National Survey. Alimentazione e stato nutrizionale. In https://www.iss.it/documents/20126/0/HBSC.pdf/97b1 cfee-444c-bfd4-ab58-d0b1dcb504fb?t=1603882812589, Accessed 13 June 2020.

52. World Health Organization. Childhood Obesity Surveillance Initiative HIGHLI GHTS 2015-17. In https://www.euro.who.int/_data/assets/pdf_file/0006/3 72426/WH14_COSI_factsheets_v2.pdf, Accessed 23 June 2020.

53. World Health Organization. Latest data shows southern European countries have highest rate of childhood obesity. In https://www.euro.who.int/en/hea Ith-topics/disease-prevention/nutrition/news/news/2018/5/latest-datashows-southern-european-countries-have-highest-rate-of-childhood-obesity, Accessed 30 June 2020.

54. Ara I, Vicente-Rodriguez G, Perez-Gomez J, Jimenez-Ramirez J, SerranoSanchez JA, Dorado C, et al. Influence of extracurricular sport activities on body composition and physical fitness in boys: a 3-year longitudinal study. Int J Obes. 2006;30(7):1062-71. https://doi.org/10.1038/sj.ijo.0803303.

55. Ekelund U, Aman J, Yngve A, Renman C, Westerterp K, Sjostrom M. Physical activity but not energy expenditure is reduced in obese adolescents: a case-control study. Am J ClinNutr. 2002;76:935-41.

56. Lobstein T, Baur L, Uauy R. Obesity in children and young people: a crisis in public health. Obes Rev. 2004;5(s1):4-104. https://doi.org/10.1111/j.1467789X.2004.00133.x

57. Hunter GR, Kekes-Szabo T, Treuth MS, Williams MJ, Goran M, Pichon C. Intraabdominal adipose tissue, physical activity and cardiovascular risk in preand post-menopausal women. Int J Obes Relat Metab Disord. 1996;20(9): 860-5.

58. Hunter GR, Kekes-Szabo T, Snyder SW, Nicholson C, Nyikos I, Berland L. Fat distribution, physical activity, and cardiovascular risk factors. Med Sci Sports Exerc. 1997;29(3):362-9. https://doi.org/10.1097/00005768-199703000-00011.

59. Roemmich JN, Clark PA, Walter K, Patrie J, Weltman A, Rogol AD. Pubertal alterations in growth and body composition. V. Energy expenditure, adiposity, and fat distribution. Am J Physiol Endocrinol Metab. 2000;279(6): E1426-36. https://doi.org/10.1152/ajpendo.2000.279.6.E1426.

60. Ara I, Vicente-Rodriguez G, Jimenez-Ramirez J, Dorado C, SerranoSanchez JA, Calbet JA. Regular participation in sports is associated with enhanced physical fitness and lower fat mass in pre-pubertal boys. Int Obes Relat Metab Disord. 2004;28(12):1585-93. https://doi.org/10.1038/sj. ijo.0802754.

61. II Servizio sanitario regionale Emilia Romagna. In https://salute.regione. emilia-romagna.it/normativa-e-documentazione/rapporti/ssr/il-servizio-sanita rio-regionale-dellemilia-romagna-le-strutture-la-spesa-le-attivita-al-31dicembre-2013-dossier-quattro-anni-di-sanita-2010-2013, Accessed 23 June 2020. 
62. Malina RM. Tracking of physical activity and physical fitness across the lifespan. Res Q Exerc Sport. 1996;67:48-57.

63. Malina RM, Katzmarzyk PT. Validity of the body mass index as an indicator of the risk and presence of overweight in adolescents. Am J Clin Nutr. 1999; 70:131s-6s.

64. Stagi S, Ibáñez-Zamacona ME, Jelenkovic A, Marini E, Rebato E. Association between self-perceived body image and body composition between the sexes and different age classes. Nutrition. 2020;82:111030.

65. Brown KM, McMahon RP, Biro FM, Crawford P, Schreiber GB, Similo SL, et al. Changes in self-esteem in black and white girls between the ages of 9 and 14 years. The NHLBI growth and health study. J Adolesc Health. 1998;23(1): 7-19. https://doi.org/10.1016/S1054-139X(97)00238-3.

66. Hesketh K, Wake M, Wake E. Body mass index and parent reported selfesteem in elementary school children: evidence for a causal relationship. Int J Obes Relat Metab Disord. 2004;28(10):1233-7. https://doi.org/10.1038/sj.jio. 0802624.

67. Franklin J, Deyner G, Steinbeck KS, Caterson ID, Hill AJ. Obesity and risk of low self-esteem: a statewide survey of Australian children. Pediatrics. 2006; 118(6):2481-7. https://doi.org/10.1542/peds.2006-0511.

68. Southall J, Okely AD, Steele JR. Actual and perceived physical competence in overweight and non-overweight children. Pediatr Exerc Sci. 2004;16(1): 15-24. https://doi.org/10.1123/pes.16.1.15.

69. Okely AD, Booth ML, Patterson JW. Relationship of physical activity to fundamental movement skills among adolescents. Med Sci Sports Exerc. 2001;33(11):1899-904. https://doi.org/10.1097/00005768-200111000-00015.

70. Ulrich BD. Perceptions of physical competence, motor competence and participation in organized sport: their interrelationships in young children. Res Q Exerc Sport. 1987;58(1):57-67. https://doi.org/10.1080/02701367.1987.1 0605421.

71. Fisher S, Abdullah A, Charvin I, Da Fonseca D, Bat-Pitault F. Comparison of body image evaluation by virtual reality and paperbased figure rating scales in adolescents with anorexia nervosa: retrospective study. Eat Weight Disord. 2020;25(3):735-43. https://doi.org/10.1007/s40519-019-00680-1.

72. Ralph-Nearman C, Arevian AC, Puhl M, Kumar R, Villaroman D, Suthana N, et al. A Novel Mobile Tool (Somatomap) to Assess Body Image Perception Pilot Tested With Fashion Models and Nonmodels: Cross-Sectional Study. JMIR Ment Health. 2019;6(10):e14115.

73. Khan AN, Khalid S, Khan HI, Jabeen M. Impact of today's media on university student's body image in Pakistan: a conservative, developing country's perspective. BMC Public Health. 2011;11:379.

74. Pimenta AM, Sánchez-Villegas A, Bes-Rastrollo M, López CN, MartínezGonzález MA. Relationship between body image disturbance and incidence of depression: the SUN prospective cohort. BMC Public Health. 2009;9(1):1. https://doi.org/10.1186/1471-2458-9-1.

75. Ralph-Nearman C, Filik R. New body scales reveal body dissatisfaction, thinideal, and muscularity-ideal in males. Am J Mens Health. 2018;12(4):740-75. https://doi.org/10.1177/1557988318763516.

76. Ralph-Nearman C, Filik R. Development and validation of new figural scales for female body dissatisfaction assessment on two dimensions: thin-ideal and muscularity-ideal. BMC Public Health. 2020;20:1114.

\section{Publisher's Note}

Springer Nature remains neutral with regard to jurisdictional claims in published maps and institutional affiliations.

Ready to submit your research? Choose BMC and benefit from:
- fast, convenient online submission
- thorough peer review by experienced researchers in your field
- rapid publication on acceptance
- support for research data, including large and complex data types
- gold Open Access which fosters wider collaboration and increased citations
- maximum visibility for your research: over 100M website views per year
At BMC, research is always in progress.
Learn more biomedcentral.com/submissions

